\title{
EFEITO DA TERAPIA FOTODINÂMICA ANTIMICROBIANA NA VIABILIDADE E VIRULÊNCIA DOS StREPTOCOCCUS MUTANS
}

\author{
Tese apresentada à Faculdade de Odontologia de \\ Ribeirão Preto da Universidade de São Paulo, para \\ obtenção do título de Doutor em Ciências. \\ Programa: Odontopediatria. \\ Área de concentração: Odontopediatria
}

Orientadora: Profa. Dra. Silmara Aparecida Milori Corona

Ribeirão Preto 
Autorizo a reprodução e divulgação total ou parcial deste trabalho, por qualquer meio convencional ou eletrônico, para fins de estudo e pesquisa, desde que citada a fonte.

\section{Ficha Catalográfica}

Elaborada pela Biblioteca Central do Campus USP - Ribeirão Preto

Nemezio, Mariana Alencar.

Efeito da terapia fotodinâmica antimicrobiana na viabilidade e virulência dos Streptococcus mutans. Ribeirão Preto, 2016.

79p.: il, $30 \mathrm{~cm}$.

Tese de Doutorado, apresentada à Faculdade de Odontologia de Ribeirão Preto/USP. Área de Concentração: Odontopediatria

Orientadora: Corona, Silmara Aparecida Milori

1. Laser de diodo. 2. Azul de metileno. 3. Streptococcus mutans. 4. Polissacarídeos 
FolHa de Aprovação

Nemezio, MA. Efeito Da Terapia Fotodinâmica Antimicrobiana na Viabilidade e Virulência dos Streptococcus Mutans.

Tese apresentada à Faculdade de Odontologia de

Ribeirão Preto da Universidade de São Paulo para obtenção do Título de Doutor em Ciências. Programa:

Odontopediatria. Área de concentração: Odontopediatria.

Data da Defesa:

1

\section{BANCA EXAMINADORA}

$\operatorname{Prof}(a) \cdot \operatorname{Dr}(a)$ :

Julgamento:

Assinatura:

$\operatorname{Prof}(a) . \operatorname{Dr}(a)$ :

Julgamento: Assinatura:

$\operatorname{Prof}(a) \cdot \operatorname{Dr}(a)$ :

Julgamento: Assinatura:

Prof(a). Dr(a):

Julgamento: Assinatura:

Prof(a). Dr(a).: Julgamento: Assinatura: 



\section{Mariana Alencar Nemezio}

\section{DAdOS CuRRICULARES}

Nascimento 25 de julho de 1986 - Maceió/AL

Filiação Luiz Marcos Nemezio

Rosilea Alencar Gouveia Nemezio

2005-2010 Graduação.

Universidade Federal de Alagoas (UFAL)

2011-2012 Aperfeiçoamento em Atendimento Odontológico a Pacientes Especiais.

Faculdade de Odontologia de Ribeirão Preto USP.

2011-2013 Especialização em Odontopediatria - Associação Odontológica de Ribeirão Preto (AORP)

2011-2013 Pós-graduação (Mestrado) em Odontologia.

Área de concentração: Odontopediatria

Faculdade de Odontologia de Ribeirão Preto/USP

2013-2016 Pós-graduação (Doutorado) em Odontologia.

Área de concentração: Odontopediatria

Faculdade de Odontologia de Ribeirão Preto/USP 

$\mathcal{D}_{\text {edicatória }}$ 



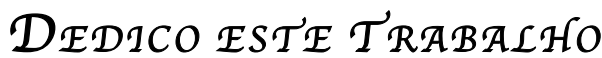

$\mathcal{A} \mathcal{D}$ eus, por ter me permitido concluir maís um sonho.

Aos meus pais, Luiz Marcos Nemezio e Rosilea Alencar Gouveia Nemezio, os melhores pais que eu podería ter. Muito obrigada por sempre me apoiarem em todos os meus sonhos. Ainda bem que vocês acredítaram neles quando eu já não acredítava mais. Apesar de toda a saudade, eu venci maís uma etapa na minha vida profissional. Com palavras não consígo expressar o quanto amo vocês e como vocês têm papel fundamental nessa conquísta. Muito obrigada pelo apoío!

Ȧ minha irmã, Maria $\mathcal{E}$ liza Alencar Nemezio, pele cuidado e conselhos, que, apesar de certos, são às vezes difíceis de serem seguidos. Você é um exemplo de profíssional. Estou esperando sua volta para trabalharmos juntas; vai ser tão divertido! Nós quatro estaremos sempre juntos, mesmo com as dificuldades. Como eu costumo dizer, você é minha segunda mãe. Sem você, não tería chegado até aquí.

$\grave{\mathcal{A}}$ minha orientadora, a querida Professora Dra. Silmara Aparecida Milori Corona. Hoje, com os othos cheíos de lágrimas e já com saudades, venho agradecer os ensinamento, a dedícação e o incentivo. Obrígada por não ter me deixado desístir e por ser essa pessoa tão especial. $\mathcal{A}$ senhora me fez acreditar em que eu fosse capaz. Quando the dei a noticia de que tinha sido contratada como professora, seu apoio foi imediato. Muito obrigada! Espero um día ser para meus alunos pelo menos um pouco do que a senhora foi para mim! Não pense que vai fícar livre, estarei em Ríbeirão Preto para fazer pesquísa. Sentirei muita saudade, mande mensagem pelo WhatsaApp, não se esqueça. Um beijo. 

$\mathcal{A}_{\text {gradecimentos }} \mathcal{E}_{\text {speciais }}$ 

Aos meus familiares, pelo amor e união. Por vocês, todas as dífículdades são vencidas e as alegrias compartilhadas. Sem vocês, não sería nada.

$\grave{\mathcal{A}}$ minha orientadora, Professora Dra. Silmara Aparecida Milori Corona. Sou muita grata a Deus por tê-la colocado em minha vida. Meus sinceros agradecimentos pelos ensinamentos, carínho e dedícação.

Ȧ Professora Dra. Carolina Patrícia $\mathcal{A}$ lves, pela amizade, paciêncía e disponibilidade para ajudar, ensinar e por disponibilizar o laboratórío de Bioquímica da Faculdade de Ciêncías Farmacêuticas.

Aos amigos-irmãos, Silvana Aparecida Fernandes Polizelí e Rodrigo Alexandre Valério, pela ajuda, companheirismo e pelas rísadas. Formamos um trío perfeito. Vocês contribuiram para meu crescimento pessoal e profissional. AMO VOC $\hat{E} S$. Obrígada pelos ensinamentos, pelas noites que não dormíram, enquanto me ajudavam a montar aulas e escrever artígos ou quando escutavam meus problemas.

$\grave{\mathcal{A}}$ querída amiga Sofia Sampaio de Souza Farias, pela amizade e parcería neste trabalho. Foram fins de semanas, feríados e muitas noites saindo tarde do laboratório, mas sempre com um boa companhia, que me fazia dar boas rísadas. Obrígada, Sofi.

’̀̀ Renata Siqueira Scatolin, amiga querida que me ajudou desde o Mestrado, Cendo tudo o que escrevia, com paciência para corrígír TUDO. Muito Obrígada. Tenho certeza de que você é uma excelente professora. Quando você defendeu o Doutorado, o Caboratórío perdeu um pouco da graça.

Ȧs amigas Katharina Morant Holanda de Oliveira, Priscilla Coutinho Romualdo e Rachel Matos, que eram a familia de Ríbeírão Preto. Quando a saudade apertava, mandavam-me ter calma. Eu admiro todas vocês. Obrígada pelas conversas, pelo futebol às quartas e pelo copo de leite quando estava tríste e não quería comer. Iá sinto falta 
da reunião na sala nos días de seminários, artígos e dos días em que não podíamos dormir Dávamos apoí umas às outras. Foram momentos de muito trabalho, mas, mesmo assím foi tudo muito divertído.

Às amigas Ana Caroline Fumes, Denise de Souza Matos, Daniele Luca Longo, Larissa Nogueira Soares Ribeiro e Késsia Mesquita Guimarães, pela familia formada durante o Mestrado e o Doutorado. Obrigada por tudo.

$\stackrel{\mathcal{A}}{ }$ Professora Dra. Cristina Borsato, pelos ensinamentos e carinho. Foi muito bom trabalhar com a senhora e conhecer o seu lado tão humano. A senhora faz um trabalho lindo.

Às técnicas do Laboratório de Bioquímica da Faculdade de Ciências Farmacêuticas Ana Cristina Morselí Polizello e Luciana Angulo Faría Rocha pela amizade, disponibilidade e paciência e pela parcería neste trabalho.

$\grave{A}$ amiga $\mathcal{A}$ na Carolina de Santos $\mathcal{R} e ́$, por me ensinar a dar os prímeíros passos na Microbiología.

À minha querida tía Rosiana Alencar Costa, por todo o apoio e pelos ensinamentos. Acho que a senhora não tem ideía de como sua ajuda foi importante para a realização deste sonho. T'e amo, tía. 
$\mathcal{A}_{\text {gradecimentos }}$ 

Ȧ Faculdade de Odontologia de Ribeirão Preto, da Universidade de São Paulo, na pessoa da atual diretora, Professora Dra. Léa Assed Bezerra da Silva e ao vícediretor, Professor Doutor Arthur Belem Novaes Júnior.

À Coordenação do Curso de Pós-Graduação da Faculdade de Odontología de Ribeirão Preto, da Universidade de São Paulo, área de concentração em Odontopediatría, na pessoa da atual Professora Dra Raquel Assed Bezerra da Silva Segato e da více-coordenadora, Professora Dra. Léa Assed Bezerra da Silva.

Ao Professor Dr. Paulo Nelson Filho, por ser exemplo de professor. Obrigada pelos ensinamentos e pelas belíssimas aulas.

$\grave{\mathcal{A}}$ Professora Dra. Aldevina Campos de Freitas, pela qual tenho uma enorme admiração. Ela está sempre disposta a ajudar e a atender, e isso é amor à profíssão.

$\grave{A}$ Professora Dra. Alexandra Mussolíno de Queiroz, pela amizade, pelo aprendizado e pela paciêncía.

$\grave{\mathcal{A}}$ Professora Dra. Andiara $\mathcal{D} e$ Rossi, pelos ensinamentos, pela amizade, paciência, e disponibilidade.

$\grave{A}$ Professora Dra. Raquel Assed Bezerra da Silva Segato, pela amizade e pelos ensinamentos.

$\grave{A}$ Professora Dra. Kranya Victoría Diaz Serrano, pela amizade e pelos ensinamentos. Obrigada por tudo!

Ao Professor Dr. José Tarcísio Lima Ferreira, por ser exemplo de profissional, pela amizade, pelos ensinamentos e por ter me acolhido na disciplina de Ortodontia. Muito Obrigada. 
Às professoras de Odontopediatria da Universidade Federal de Alagoas, Maria Dânia Holanda Tenório, Patricia Batista Lopes do Nascimento e Lucineide de Melo Santos, por me ensinarem a amar o que eu faço.

Ao professor de Ortodontía da Universidade Federal de Alagoas, Jovenildo Wanderley Santos, pela dedicação e pelo incentivo, pela amizade, pelos conselhos e por mostrar que, com dedicação, podemos realizar nossos sonhos.

Aos amigos do departamento de Odontopediatria e Odontología Restauradora Daniel Galafassi, Taisa Lepri, e Sandra Chiga Carvalho, Taisa Penazzo Leprí, Cesar Penazzo Lepri, Mirian Saavedra, Leticia Bignardí, Aline Morí, Isabela Lima, Caroline Maschieto Pucinellí, Cintia Guimarães de $\mathcal{A}$ lmeida, Claudía Maria Carpio Bonilla, Daniela Silva Barroso, Danielly Cunha Araújo Ferreira, Driely Barreiros, Elaine Machado Pingueiro, Francine Lorencetti da Silva, Julíana Arid, Leonardo Gontijo Matos, Maria Gabriela Flores Bracho, Mariana Oliveira Daltóe, Mariele Andrade, Marina Mocardini Vilela, Paula Regina Ávila Silvano, Talitha de Síqueira Mellara, Sara Silva de Oliveira, Isabella Rodrigues Ziotti, Giselle Leite, Danielle Azevedo, Marina Sena, Marta Contente, Camila Scatena, Lídía Regina da Costa, Fabiana $\mathcal{A}$ lmeida Curylofo Zottí, pela amizade e ajuda.

As queridas amigas Juliana Jendiroba Faraoni Romano, Júlia Olien Sanches, pelas risadas sempre garantídas no laboratório. T'rabalho divertído é muito melhor.

Ao Professor Doutor Rodrigo Galo, pela amizade, paciência, disponíbilidade e pelo auxilio. 
À CAPES (Coordenação de Aperfeiçoamento de Pessoal de Nivivel Superior), pela bolsa concedída.

$\dot{\mathcal{A}}$ Professora Doutora Sandra Y. F. Alves, pelos ensinamentos no inicio do Mestrado.

Aos funcionários do Departamento de Clinica Infantil da Faculdade de Odontología de Ribeirão Preto: Filomena L. Placcit, Michelí Cristina L. Rovanholo, Matheus M. Zanela, Francisco Wanderley G. de Paula e Silva, Carolina $\mathcal{P}$. T. Mantovaní, Marco Antônío dos Santos, Marílía P. Lucísano, Carmo Euripedes $\mathcal{T}$. Barretto, Nilza Leticia Magalhães, Fátima A. Rizoli, Fátima A. Jacinto Daniel e Renata $\mathcal{A}$. Fernandes. Obrigada pela disponíbilidade, paciêncía e ajuda.

Ȧ Patrícía Marchi, técnica do Departamento Odontologia Restauradora da Faculdade de Odontología de Ribeirão Preto - USP, pela amizade.

Aos docentes do departamento de Clínica Infantil e Social da Faculdade de Odontologia de Ríbeirão Preto, São Paulo, Professoras Doutoras Aldevina Campos de Freitas, Alexandra Mussolino de Queiroz, Andiara De Rossi, Kranya Víctoría Díaz Serrano, Léa Assed Bezerra da Silva, María Crístina Borsatto, Raquel Assed Bezerra da Silva, Sada Assed, Maria Bernadete Sasso Stuani, Mirian Aiko Nakane Matsumoto, Maria da Conceição Pereira Saraiva e aos Professores Doutores Paulo Nelson Filho, Adílson Tomasin, Fábio Lourenço Romano, José Tarcísio Lima Ferreira e Fabrício Kitazono de Carvalho pelos ensinamentos e pela atenção. 
À Professora de Português, Ana Rachel Cavalieri Bittar, pela correção do texto.

Ȧ Rosemary $\mathcal{A}$ lves, pela paciêncía, amizade e formatação dessa tese de Doutorado.

$\mathcal{E}$ a todos que não mencionei aquí, mas que contríbuiram para a realização deste sonho. 
$S_{\text {umário }}$ 

Resumo

ABSTRACT

1. INTRODUÇÃO

2. ProposiçÃo

3. MATERIAL E MÉTODO

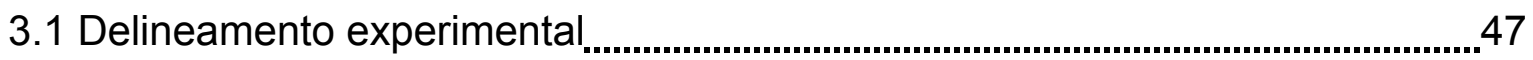

3.2 Confecção dos corpos de prova de resina acrílica ............................................. 47

3.3 Formação do biofilme de S. mutans ................................................................... 48

3.4 Tratamentos realizados nos biofilmes de S. mutans .......................................... 49

3.5 Coleta do biofilme S. mutans e análises .......................................................... 50

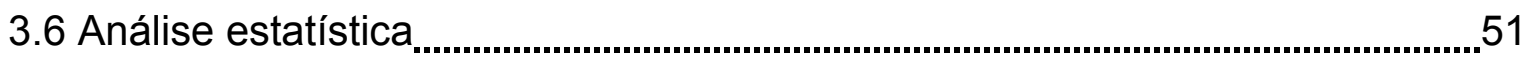

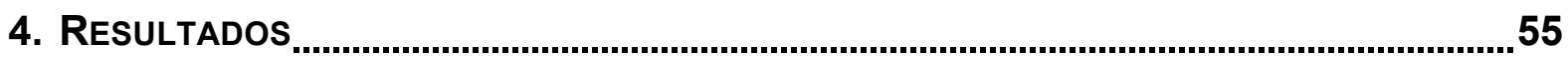

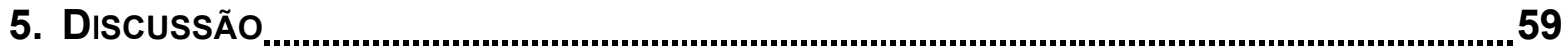

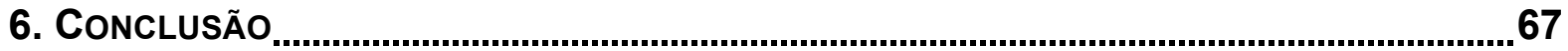

REFERÊNCIAS 

$\boldsymbol{R}_{\text {esumo }}$ 

Nemezio, M.A. Efeito da Terapia Fotodinâmica Antimicrobiana na Viabilidade e Virulência dos Streptococcus mutans. Ribeirão Preto, 2016. 79p. [Tese de Doutorado]. Ribeirão Preto: Faculdade de Odontologia da Universidade de São Paulo; 2016.

O objetivo do presente estudo foi avaliar o efeito da Terapia Fotodinâmica Antimicrobiana (aPDT) com a utilização de azul de metileno a 0,01\%, combinado ao laser de diodo, na viabilidade e na produção de polissacarídeos, de biofilmes de $S$. mutans. Biofilmes de cepas de S. mutans UA159 foram cultivados em discos de resina acrílica e expostos oito vezes por dia, durante $1 \mathrm{~min}$, à solução de sacarose a $10 \%$. Após 48 horas da formação do biofilme, as amostras foram distribuídas aleatoriamente em relação aos tratamentos $(n=4)$ : aplicação de solução salina a 0,9\% (controle negativo), aplicação de $0,12 \%$ de digluconato de clorexidina (controle positivo), ou aplicação da terapia fotodinâmica antimicrobiana. Para aplicação da terapia fotodinâmica antimicrobiana, foi utilizado azul de metileno a $0,01 \%$, combinado ao laser de diodo com comprimento de onda de $660 \mathrm{~nm}$. Foram usados os seguintes parâmetros: área da secção transversal do feixe de laser $0,028 \mathrm{~cm}^{2}$, potência de $100 \mathrm{~mW}$, energia de $9 \mathrm{~J}$, densidade de energia de $320 \mathrm{~J} / \mathrm{cm}^{2}$, durante 90s. Os tratamentos foram realizados duas vezes ao dia. Após $120 \mathrm{~h}$, os biofilmes de $S$. mutans formados sobre cada disco de resina acrílica foram coletados, de modo a determinar o número de bactérias viáveis e a concentração do polissacarídeo extracelular insolúvel $(\mathrm{PECI})$ e do polissacarídeo intracelular (PIC). A análise variância um critério (ANOVA) e o teste de Tukey revelaram que as contagens das bactérias nos biofilmes formados foram significativamente diferentes entre os tratamentos. A aPDT mostrou inibição do crescimento do biofilme, quando comparado ao grupo do $\mathrm{NaCl}(p<0,05)$. A concentração de PECl e PIC foi maior no biofilme exposto ao $\mathrm{NaCl}$ do que a encontrada nos outros grupos $(p<0,05)$ e não foi observada diferença significativa entre os grupos digluconato de clorexidina e aPDT $(p>0,05)$. De acordo com as condições experimentais do presente estudo, sugere-se que o tratamento realizado duas vezes ao dia com aPDT utilizando-se azul de metileno a 0,01\%, combinado ao laser de diodo $\left(\lambda=660 \mathrm{~nm} ; 320 \mathrm{~J} / \mathrm{cm}^{2} ; 100 \mathrm{~mW}\right.$; 90s; 9J), diminui a viabilidade do biofilme e afeta sua organização estrutural.

Palavras-chave: laser de diodo, azul de metileno, Streptococcus mutans, polissacarídeos. 

$\mathcal{A}_{\text {bstract }}$ 

Nemezio, M.A. Effect of Methylene Blue induced Photodynamic Therapy on Biofilm Viability and Virulence Factors of Streptococcus Mutans. Ribeirão Preto, 2016. 79p. [Tese de Doutorado]. Ribeirão Preto: Faculdade de Odontologia da Universidade de São Paulo; 2016.

The aim of this study was to evaluate the effect of Antimicrobial Photodynamic Therapy (aPDT) using methylene blue $0.01 \%$ combined with diode laser on biofilm viability and polysaccharides produced by Streptococcus mutans. S. mutans UA 159 biofilms were grown on acrylic resin discs and exposed eight times/day for $1 \mathrm{~min}$ in a $10 \%$ sucrose solution. After the biofilms were allowed to grow for $48 \mathrm{~h}$, they were treated two times/day according to the treatments $(n=4): 0.9 \%$ saline solution (negative control), $0.12 \%$ chlorhexidine digluconato (positive control) or Antimicrobial Photodynamic Therapy (aPDT). For the application of Antimicrobial Photodynamic Therapy has been used methylene blue $0.01 \%$ in combination with the diode laser with $660 \mathrm{~nm}$ wavelength. The parameters adopted were: spot size of $0.028 \mathrm{~cm}^{2}$, fixed output power of $100 \mathrm{~mW}$, energy density of $320 \mathrm{~J} / \mathrm{cm}^{2}$, time exposure of $90 \mathrm{~s}$ and energy of $9 \mathrm{~J}$. Treatments were performed twice daily. After $120 \mathrm{~h}$ of growth, the biofilm formed on each disc was collected to determine the number of viable bacteria, and concentration of the insoluble exopolysaccharide (IEPS) and intracellular polysaccharide (IPS). The analysis of variance one-way (ANOVA) and Tukey test revealed that the counts of bacteria in the biofilms formed differ significantly among the treatments and aPDT showed biofilm inhibition when compared to $\mathrm{NaCl}$ group $(p<0.05)$. The concentration of IEPS and IPS was higher in biofilm exposed to $\mathrm{NaCl}$ than that found in the other groups $(p<0.05)$ and no significant difference was observed among $\mathrm{CHX}$ and aPDT groups ( $p>0.05)$. According to experimental conditions of the present work, the results suggest that a twice-daily treatment with aPDT using methylene blue $0.01 \%$ in combination with the diode laser $(\lambda=660 \mathrm{~nm}$, $320 \mathrm{~J} / \mathrm{cm}^{2}, 100 \mathrm{~mW}, 90 \mathrm{~s}$; 9J) decreases biofilm viability and affects its structural organization.

Keywords: diode laser, methylene blue, Streptococcus mutans, polysaccharides. 

$I_{\text {ntrodução }}$ 



\section{INTRODUÇÃO}

A cárie é uma doença relacionada à formação do biofilme dentário maduro, formado pela interação de bactérias específicas com os constituintes da dieta (Bowen, 2002). Os biofilmes são comunidades microbianas ligadas a uma superfície e embebidas numa matriz de polissacarídeos. As bactérias aderidas podem crescer e uma comunidade microbiana complexa se desenvolve (Klein et al., 2015).

Os carboidratos da dieta foram identificados como os principais responsáveis pelas alterações nos biofilmes dentais, servindo como substrato para a síntese de polissacarídeos extracelulares insolúveis (PECI) e intracelulares (PIC) que podem provocar um $\mathrm{pH}$ ácido, tornando a microflora residente do biofilme oral cariogênica (Bowen, 2002; Marsh, 1991). O biofilme cariogênico é formado principalmente por S. mutans e lactobacilos (De Stoppelaar et al., 1970; Staat et al., 1975). Em pH ácido, esses micro-organismos são competitivos e inibem o crescimento e/ou metabolismo de bactérias não cariogênicas (Bradshaw; Marsh, 1998).

A cárie dentária é uma doença biofilme-dependente (Bowen, 2015). A desorganização do biofilme impede a progressão da cárie e pode ser realizada pela ação mecânica e/ou química (Loe; Silness, 1963; Kumar; Green, 2005). Todavia, uma vez que os biofilmes são formados, eles tornam-se mais resistentes ao tratamento com agentes antimicrobianos, se comparados a células planctônicas (Marsh, 2004). Dessa forma, terapias com o objetivo de diminuir ou mesmo impedir a formação do biofilme cariogênico são importantes para o controle da doença cárie dentária. 
O digluconato de clorexidina é considerado o antimicrobiano padrão ouro na Odontologia (Twetman, 2004). Em baixas concentrações, seu efeito é dosedependente e tem atividade bacteriostática, ao passo que, em altas concentrações, tem atividade bactericida (Jenkins et al., 1988; Karpiński; Szkaradkiewicz, 2015). O digluconato de clorexidina é uma molécula catiônica que se liga de forma não específica aos fosfolipídios da parede celular bacteriana carregada negativamente. Em baixas concentrações, esse antimicrobiano altera a integridade da membrana celular, resultando no extravasamento de componentes bacterianos de baixo peso molecular, como o potássio e fósforo (Hidalgo; Dominguez, 2001). Já em altas concentrações, pode provocar a morte celular por precipitação ou coagulação das proteínas citoplasmáticas (Varoni et al., 2012). No entanto, seu emprego a longo prazo é contraindicado devido aos efeitos colaterais locais, como coloração extrínseca dos dentes e língua (Watts; Addy, 2001), alteração do paladar (Flötra et al., 1973), aumento da formação de cálculo supragengival (Lang et al., 1982) e, menos frequentemente, descamação da mucosa oral (Flötra et al., 1973). Devido a esses efeitos secundários, outras terapias, como aPDT, vem sendo estudada como uma nova alternativa para o controle da doença cárie.

O principal fator que pode dificultar a difusão e acesso do agente antimicrobiano é o polissacarídeo (Thurnheer et al., 2003). Em particular, o polissacarídeo extracelular insolúvel (PECI) contribui para a formação, estabilidade e integridade estrutural do biofilme, estando associado à prevalência da cárie dentária (Nobre dos Santos et al., 2002; Parisotto et al., 2015). Outro fator de virulência bacteriana importante é o polissacarídeo intracelular (PIC). O PIC pode ser empregado como uma fonte de carboidratos para a fermentação em condições de escassez de nutrientes e é utilizado por bactérias para prolongar a produção de ácido, que 
contribui para a progressão da lesão cariosa (Busuioc et al., 2009). Considerando que o S. mutans é a bactéria mais cariogênica (Hamada; Slade, 1980) e pode utilizar a sacarose da dieta para sintetizar polissacarídeos (Paes-Leme et al., 2006), a análise desse fator de virulência é importante para a avaliação de novas terapias para controle do biofilme cariogênico, como a aPDT.

A aPDT vem sendo estudada e considerada para controlar os biofilmes (Zanin et al., 2005; Zanin et al., 2006; Teixeira et al., 2012; Schneider et al., 2012; Araújo et al., 2014; Quishida et al., 2015a; Quishida et al., 2015b; Araújo et al., 2015). Essa terapia é baseada na interação de uma fonte de luz com um fotossensibilizador, que, na presença de oxigênio, causa toxicidade na bactéria por meio da geração de oxigênio singleto e radicais livres que são citotóxicos para esses micro-organismos. Nesse tipo de terapia, a morte das bactérias é causada principalmente por danos ao DNA e à membrana celular (Soukos; Goodson, 2011).

Para que essa terapia possa ser efetiva, é necessário que a molécula do fotossensibilizador absorva fótons de luz que saem do seu estado fundamental para o estado excitado (singleto) (Dougherty et al., 1998; Konan et al., 2002). A molécula, no estado singleto, pode voltar ao estado fundamental, emitindo um fóton de energia luminosa (fluorescência), ou ser convertida a um estado excitado tripleto (Ochsner, 1997).

No estado tripleto, a energia pode ser dissipada por meio da fluorescência, retornando ao seu estado fundamental, ou pode atuar por meio de dois tipos de reações que necessitam de oxigênio (Ochsner, 1997). Na reação tipo I, observa-se uma transferência de elétrons do fotossensibilizador no estado tripleto ao substrato, provocando reações de óxido-redução com as biomoléculas e produção de espécies reativas de oxigênio, como superóxido, hidroxilas e radicais derivados de lipídios 
(Athar et al., 1988). A reação do tipo II envolve transferência de energia do fotossensibilizador no estado tripleto para a molécula de oxigênio, produzindo oxigênio no estado singleto, que pode oxidar moléculas biológicas, como as proteínas, os ácidos nucleicos e lipídios, causando citotoxidade (Redmond; Gamlin, 1999).

Na Periodontia, foi demostrada a eficácia dessa terapia para a redução do número de bactérias periodontopatogênicas em estudos in vitro (Goulart et al., 2010; Street et al., 2010) e in vivo (Kömerik et al., 2003; Oliveira et al., 2009; Sigusch et al., 2010; Cappuyns et al., 2012; Novaes et al., 2012; Monzavi et al., 2016). Observaram-se resultados promissores com a utilização do laser de diodo associado ao azul de metileno como terapia auxiliar nos tratamentos básicos de raspagem e alisamento radicular (Sigusch et al., 2010; Cappuyns et al., 2012; Novaes et al., 2012; Monzavi et al., 2016). No que se refere às lesões cariosas, parece que essa terapia poderia ser utilizada tanto na prevenção, como na Odontologia minimamente invasiva, a fim de reduzir o número de bactérias remanescentes após preparos cavitários (Wilson, 2004; Guglielmi et al., 2011; Araújo et al., 2015).

Estudos laboratoriais demonstraram que a terapia fotodinâmica pode ser efetiva na redução do número de bactérias cariogênicas na fase planctônica (Burns et al., 1993; Burns et al., 1994; Burns et al., 1995; Bevilacqua et al., 2007; Costa et al., 2010), sob a forma de modelos de biofilmes in vitro (Zanin et al., 2005; Zanin et al., 2006; Wood et al., 2006; Mang et al., 2012; Pereira et al., 2011; Ricatto et al., 2014; Diniz et al., 2015), na redução do número de micro-organismos de amostras de placa bacteriana supragengival de humanos (O'Neill et al., 2002), in situ (Wood et al., 1999; Lima et al., 2009) e clínicos para redução de bactérias nas lesões de cárie (Guglielm et al., 2011; Araújo et al., 2015). No entanto, há trabalhos que mostram 
que há limitação dessa terapia na redução de estreptococos presentes em biofilmes de múltiplas espécies in situ (Teixeira et al., 2012) e que a fotossensibilização letal pode ocorrer predominantemente na camada mais externa do biofilme (O'Neill et al., 2002).

Na literatura existe um consenso de que o efeito antimicrobiano de um agente sobre bactérias cultivadas in vitro é apenas um possível indicativo do potencial antimicrobiano, uma vez que bactérias organizadas sob a forma de biofilme apresentam um aumento da resistência a esses agentes (Mah et al., 2001). Conforme demonstrado, apesar de diversos estudos terem obtido resultados positivos no que se refere ao uso da aPDT na prevenção das lesões de cárie dentária e no controle de bactérias cariogênicas, poucos estudos avaliaram se, além de reduzir a viabilidade, a aPDT pode influenciar na virulência dos $S$. mutans.

A aPDT idealmente deve ser utilizada em sítios específicos, pois a utilização da luz visível atinge o tecido-alvo de forma localizada (Dai et al., 2009), o que é interessante para a Odontologia. No entanto, a eficácia da aPDT é dependente de vários fatores, como tipos de luz, parâmetros do laser e interação com o fotossensibilizador (Santin et al., 2014).

$\mathrm{Na}$ literatura, pode-se observar que diferentes fontes de luz são utilizadas na aPDT, sendo o diodo emissor de luz (LED) (Zanin et al., 2005; Zanin et al., 2006; Araújo et al., 2014; Teixeira et al., 2012; Hakimiha et al., 2014) e o laser de diodo os mais utilizados (Burns et al.,1994; Wilson et al., 1996; Guglielmi et al., 2011; Pereira et al., 2011; Hakimiha et al., 2014; Ricatto et al., 2014). Essa variedade também é vista com relação aos fotossensibilizadores, e, dentre eles, os corantes azuis são os mais frequentemente usados (O'Neill et al., 2002; Zanin et al., 2005; Zanin et al., 2006; Bevilacqua et al., 2007; Lima et al., 2009; Pereira et al., 2011; Guglielmi et al., 
2011; Schneider et al., 2012; Rolim et al., 2012; Ricatto et al., 2014; Araújo et al., 2015; Diniz et al., 2015). O azul de metileno e o azul de toluidina também são conhecidos como sais fenotiazínicos e são capazes de absorver eficientemente a luz vermelha, sendo o azul de metileno um dos corantes mais utilizados em trabalhos experimentais e aplicações clínicas em odontologia (Cieplik et al., 2014).

Estudos têm mostrado que os lasers de diodo combinados com azul de metileno são capazes de promover a fotossensibilização letal de bactérias cariogênicas (Ricatto et al., 2014; Diniz et al., 2015). Além disso, imagens de microscopia confocal de varredura a laser de biofilmes de Enterococcus faecalis, após a exposição à aPDT com a utilização do azul de metileno combinado ao laser de diodo, sugeriram a ocorrência de um grande dano na estrutura do biofilme (Kishen et al., 2010; Garcez et al., 2013), provavelmente devido à influência do conteúdo do polissacarídeo. No entanto, o efeito dessa estratégia sobre os PECI e PIC dos $S$. mutans não foi estabelecido.

Dessa forma, as hipóteses nulas a serem testadas foram: (1) aPDT, utilizando azul de metileno combinado com o laser de diodo, pode inativar biofilme de $S$. mutans; (2) aPDT, utilizando azul de metileno combinado com o laser de diodo, é capaz de reduzir PECl; (3) aPDT, utilizando azul de metileno combinado com o laser de diodo, é capaz de reduzir PIC. 
$\mathcal{P}_{\text {roposição }}$ 



\section{PROPOSIÇÃO}

O objetivo do presente estudo foi avaliar o efeito da Terapia Fotodinâmica Antimicrobiana (aPDT) com a utilização do azul de metileno a 0,01\%, combinado ao laser de diodo $\left(\lambda=660 \mathrm{~nm} ; 320 \mathrm{~J} / \mathrm{cm}^{2} ; 100 \mathrm{~mW} ; 90 \mathrm{~s} ; 9 \mathrm{~J}\right)$, na viabilidade e na produção de polissacarídeos de biofilmes de Streptococcus Mutans. 

Materiale $\mathcal{M}_{\text {étodo }}$ 



\section{MAterial e MÉtodo}

\subsection{Delineamento experimental}

O fator em estudo foi tratamento realizado nos biofilmes de $S$. mutans UA159 em 3 níveis $(n=4)$ : aplicação de $0,9 \%$ de solução salina $(\mathrm{NaCl})$, controle negativo; aplicação de $0,12 \%$ de digluconato de clorexidina, controle positivo; ou aplicação terapia fotodinâmica antimicrobiana.

Para o controle do biofilme dentário cariogênico com a terapia fotodinâmica antimicrobiana foi utilizado o azul de metileno $(0,01 \%)$ combinado ao laser de diodo $\left(\lambda=660 \mathrm{~nm} ; 320 \mathrm{~J} / \mathrm{cm}^{2} ; 100 \mathrm{~mW} ; 90 \mathrm{~s} ; 9 \mathrm{~J}\right)$

O delineamento foi realizado em blocos completos e casualizados e as variáveis de respostas foram obtidas por meio da análise quantitativa do número de bactérias viáveis e da concentração do polissacarídeo extracelular insolúvel (PECI) e do polissacarídeo intracelular (PIC).

\subsection{Confecção dos corpos de prova de resina acrílica}

Matrizes de teflon fabricadas na oficina de precisão da Universidade de São Paulo de Ribeirão Preto foram utilizadas para a confecção dos 12 corpos de provas de resina acrílica autopolimerizável (JET - Artigos Odontológicos Clássico Ltda, SP, Brasil). Esses corpos de prova foram preparados de acordo com as instruções do fabricante.

As matrizes de teflon foram utilizadas para padronização dos corpos de prova ( $3 \mathrm{~mm}$ de diâmetro e $2 \mathrm{~mm}$ de altura); assim, uma irradiação uniforme do biofilme foi obtida. 
Os corpos de prova foram esterilizados por radiação de raios-X (Rad Source modelo RS 2000, Biological System, Suwanee, EUA). Foram utilizados o seguintes parâmetros: $100 \mathrm{~Gy}$, energia média de prótons de $160 \mathrm{kV}, 25 \mathrm{~mA}, 0,3$ milímetros filtro Cu por 760 segundos.

\subsection{Formação do biofilme de S. mutans}

Para a formação do biofilme dentário cariogênico in vitro, foi empregado o protocolo de produção de biofilme monoespécie em modelo "Miséria e Fartura", descrito por Ccahuana-Vásquez e Cury (2010), com duração de 5 dias. Cepas de Streptococcus mutans UA159, gentilmente cedidas pelo Prof. Jaime A. Cury, da FOP-UNICAMP, foram transferidas para um meio de baixo peso molecular (LMW), o UTYEB (Meio de Extrato de levedura Triptona), contendo glicose $1 \%$ e incubadas em estufa de anaerobiose (Sanyo Eletric Biomedical Co., Ltd., Osaka, Japão), a $37^{\circ} \mathrm{C}$ e $5 \%$ de $\mathrm{CO}_{2}$, com o objetivo de reativar os micro-organismos. Em seguida, foi realizado um "streak" desse caldo em placas de Brain Heart Infusion (BHI) Ágar, as quais ficaram mantidas em estufa $\left(37^{\circ} \mathrm{C}, 5 \%\right.$ de $\left.\mathrm{CO}_{2}\right)$. Com o auxílio de uma alça descartável, foi realizado o preparo da cultura iniciadora ("starter"). Foram coletadas colônias de uma placa de BHI ágar e essas colônias foram transferidas assepticamente para um novo meio de LMW e glicose. Esse meio contendo as colônias foi mantido em estufa $\left(37^{\circ} \mathrm{C}, 5 \%\right.$ de $\left.\mathrm{CO}_{2}\right)$. Doze espécimes foram incubadas individualmente em poços contendo $2 \mathrm{~mL}$ da mistura de meio LMW, glicose e das bactérias da cultura iniciadora e colocados em estufa $\left(37^{\circ} \mathrm{C}, 5 \%\right.$ de $\mathrm{CO}_{2}$ ). Os biofilmes formados foram transferidos para novos poços contendo um novo meio LMW e glicose, e foram expostos durante $1 \mathrm{~min}, 8 x /$ dia, à solução de sacarose $10 \%$, em horários pré-determinados $(08: 00,09: 30,11: 00,12: 30,14: 00,15: 30,17: 00$ 
e 18:30h). Esse protocolo foi repetido por mais 3 dias e, após cada exposição à sacarose, os espécimes com biofilme foram lavados em $\mathrm{NaCl}$ 0,9\% (Fluxograma 1).

O biofilme foi submetido aos métodos de controle do biofilme (tratamentos) 2 vezes ao dia (8:00 e 17:00), após o banho de sacarose. A troca do meio foi realizada a cada 24 horas. Durante o processo de formação do biofilme e da realização dos tratamentos, foi realizado o método de Coloração Gram em um esfregaço inoculado. O LMW foi analisado com microscópio óptico de luz (Olympus Corporation, Tóquio, Japão), a fim de controlar a pureza da cultura de S.mutans.

\subsection{Tratamentos realizados nos biofilmes de $S$. mutans}

Os tratamentos foram realizados duas vezes ao dia, antes da primeira e da última exposição à sacarose. Após cada tratamento, os biofilmes foram lavados três vezes em solução de $\mathrm{NaCl} 0,9 \%$.

Para a realização da aPDT, os corpos de prova foram imersos em placas de cultura contendo azul de metileno (Chimiolux - 0,01\%, DMC, São Carlos - SP) e mantidos no escuro durante 5 min (tempo de pré-irradiação) (Guglielmi et al., 2011). Após esse período, os corpos de prova foram colocados em um dispositivo fixo, fabricado na oficina de precisão da Universidade de São Paulo de Ribeirão Preto, com o objetivo de manter os copos de provas imóveis. Em seguida, eles foram irradiados com laser de diodo com comprimento de onda de $660 \mathrm{~nm}$ (Whitening Lase II - DMC Equipamentos, São Paulo, Brasil). Os parâmetros usados foram: área da secção transversal do feixe laser $0.028 \mathrm{~cm}^{2}$, potência de $100 \mathrm{~mW}$, energia de 9J, densidade de energia de $320 \mathrm{~J} / \mathrm{cm}^{2}$, durante 90s (Guglielmi et al., 2011). Foi estabelecida uma distância de $2 \mathrm{~mm}$ entre a ponta do laser e os corpos de prova. Foram realizadas 2 irradiações, uma anterior e outra posterior. 
A solução de digluconato de clorexidina 0,12\% (Sigma-Aldrich, St. Louis, MO, EUA) e a solução de $\mathrm{NaCl}$ a $0,9 \%$ (Merck Millipore Corporation, Darmstadt, Alemanha) foram preparadas em água destilada estéril e aplicadas nos biofilmes durante 1 minuto.

\subsection{Coleta e análise do biofilme S. mutans}

No sexto dia, os discos foram lavados três vezes em $\mathrm{NaCl}$ 0,9\% para remoção do material fracamente aderente e transferidos individualmente para tubos de microcentrífuga contendo $1 \mathrm{ml}$ de $\mathrm{NaCl}$ a $0,9 \%$, com os biofilmes aderidos, soltos por sonicador (Aires et al., 2008). Alíquotas de 100 $\mu \mathrm{L}$ da amostra sonicada foram diluídas em $\mathrm{NaCl}$ a $0,9 \%$ e diluições decimais seriadas foram inoculadas em duplicata pela técnica da gota de contagem (Tenuta et al., 2006) em Brain Heart Infusion (BHI) Ágar. As placas de $\mathrm{BHI}$ foram incubadas em $5 \%$ de $\mathrm{CO}_{2}$ a $37^{\circ} \mathrm{C}$, durante 48 h. As unidades formadoras de colônias (UFC) foram contadas e os resultados expressos em CFU/mm² de área de amostra.

Os polissacarídeos PECI e PIC foram determinados de acordo com procedimentos publicados (Aires et al., 2008). Para a extração de polissacarídeos, foi utilizada uma alíquota de $400 \mu \mathrm{L}$ de biofilme sonicado, que foi centrifugada a $10.000 \mathrm{~g}$, por $5 \mathrm{~min}, \mathrm{a} 4^{\circ} \mathrm{C}$. O sobrenadante foi descartado e o pellet foi agitado, por 15 min e centrifugado e o sobrenadante transferido para um tubo chamado PECI. O pellet foi lavado com $100 \mu \mathrm{L}$ de $\mathrm{NaOH} 1 \mathrm{M}$, centrifugado e o sobrenadante foi adicionado ao tubo $\mathrm{PECl}$ contendo 3 vol. de etanol resfriado. Para o tubo da microcentrífuga contendo o pellet residual, foram adicionados $400 \mu \mathrm{L}$ de $\mathrm{NaOH} 1 \mathrm{M}$ para a extração do PIC. Esse tubo foi agitado em vórtex, aquecido a $100^{\circ} \mathrm{C}$ em banho-maria durante $15 \mathrm{~min}$, centrifugado, e o sobrenadante transferido para outro 
tubo chamado PIC. O pellet foi lavado com $100 \mu \mathrm{L}$ de $\mathrm{NaCl} 0,9 \%$, centrifugado e o sobrenadante adicionado ao tubo PIC, ao qual foram acrescentados 3 vol. de etanol resfriado. Ao pellet foram acrescentados $400 \mu \mathrm{L}$ de $\mathrm{NaOH} 1 \mathrm{M}$ para a extração de polissacarídeos insolúveis (PIC). Os tubos contendo etanol resfriado e polissacarídeos foram mantidos a $-20^{\circ} \mathrm{C}$ por $30 \mathrm{~min}$, centrifugados e os pellets foram lavados duas vezes com etanol resfriado a $70 \%$. Os polissacarídeos precipitados foram ressuspensos em $250 \mu \mathrm{L} \mathrm{NaOH} 1 \mathrm{M}$ e os carboidratos totais foram estimados por meio do método de fenol sulfúrico (Dubois et al., 1956), utilizando-se como padrão a glicose. Os resultados foram normalizados para o peso úmido.

\subsection{Análise estatística}

A análise da variância, um critério (ANOVA) foi utilizada para testar o efeito dos tratamentos, enquanto o teste de Tukey foi aplicado para comparar as médias das variáveis significativas. A suposição de aderência dos resíduos para a distribuição de Gauss foi avaliada pelo teste de Shapiro-Wilk, pelo coeficiente de assimetria, curtose, e por análise gráfica. Apenas em CFU os dados originais não apresentam aderência para a distribuição de Gauss. Os testes estatísticos foram aplicados aos dados de classificação transformada, o que resulta numa distribuição normal dos resíduos. As análises estatísticas foram realizadas utilizando-se SAS (SAS Institute Inc., versão 9.3, Cary, NC, EUA) e em todos os testes estatísticos adotou-se o nível de significância de 5\%. 


\section{Fluxograma do experimento}
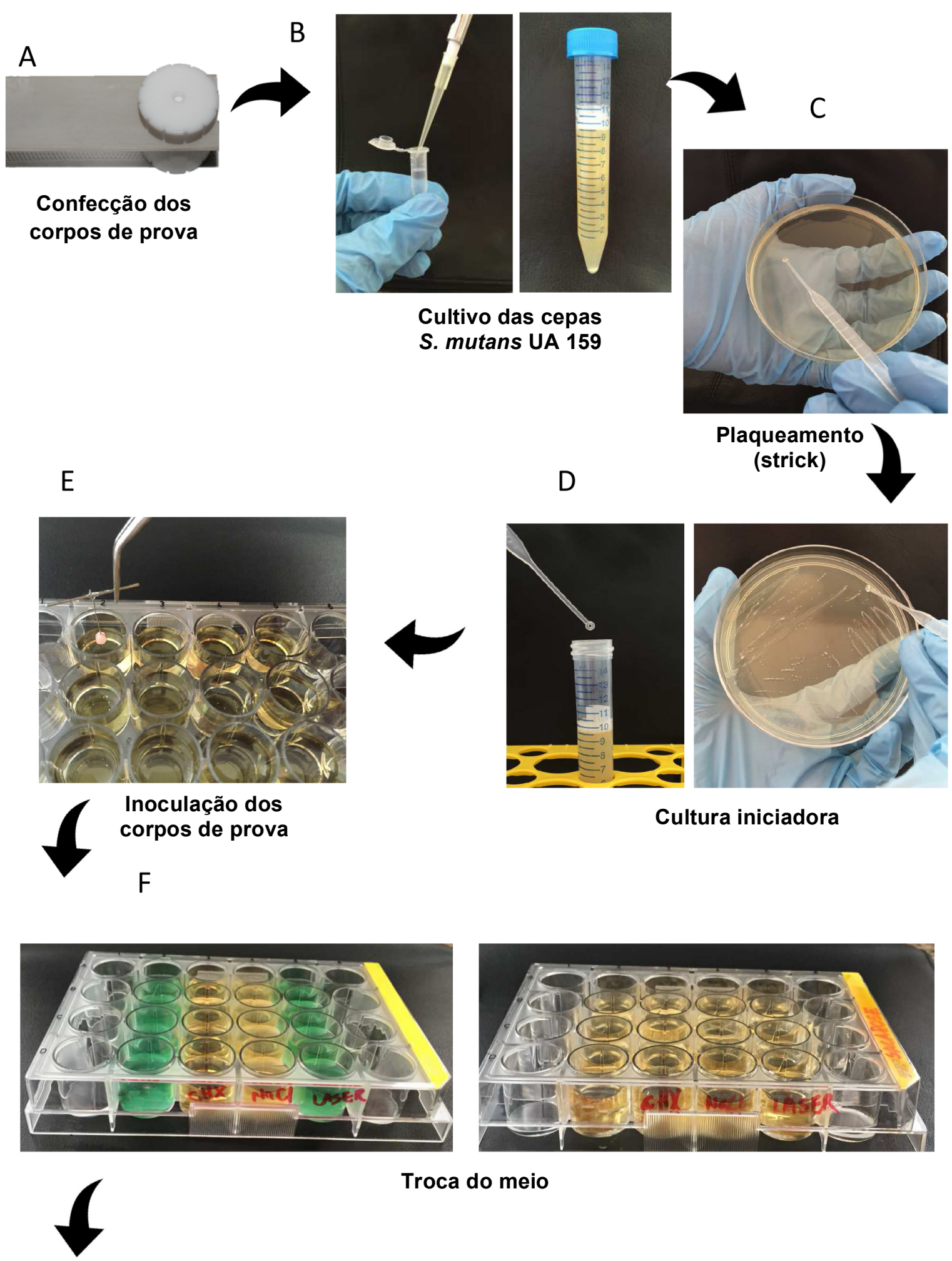

Troca do meio 
G
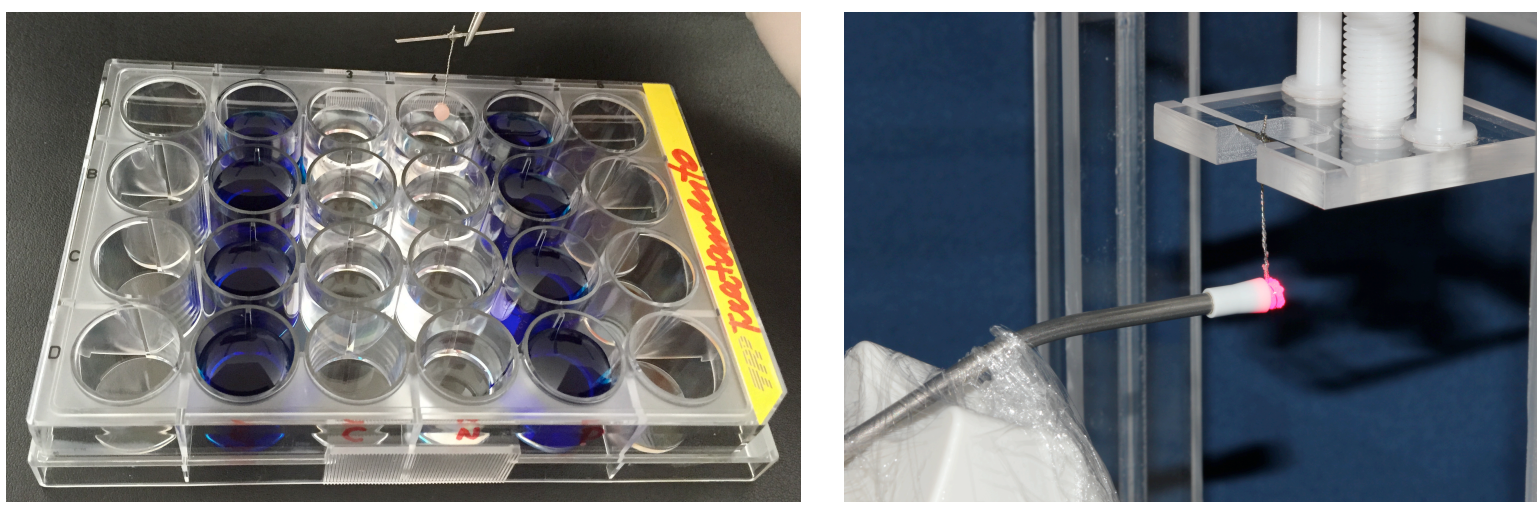

Tratamentos ( $\mathrm{NaCl}$, Clorexidina e aPDT)

$\mathrm{H}$
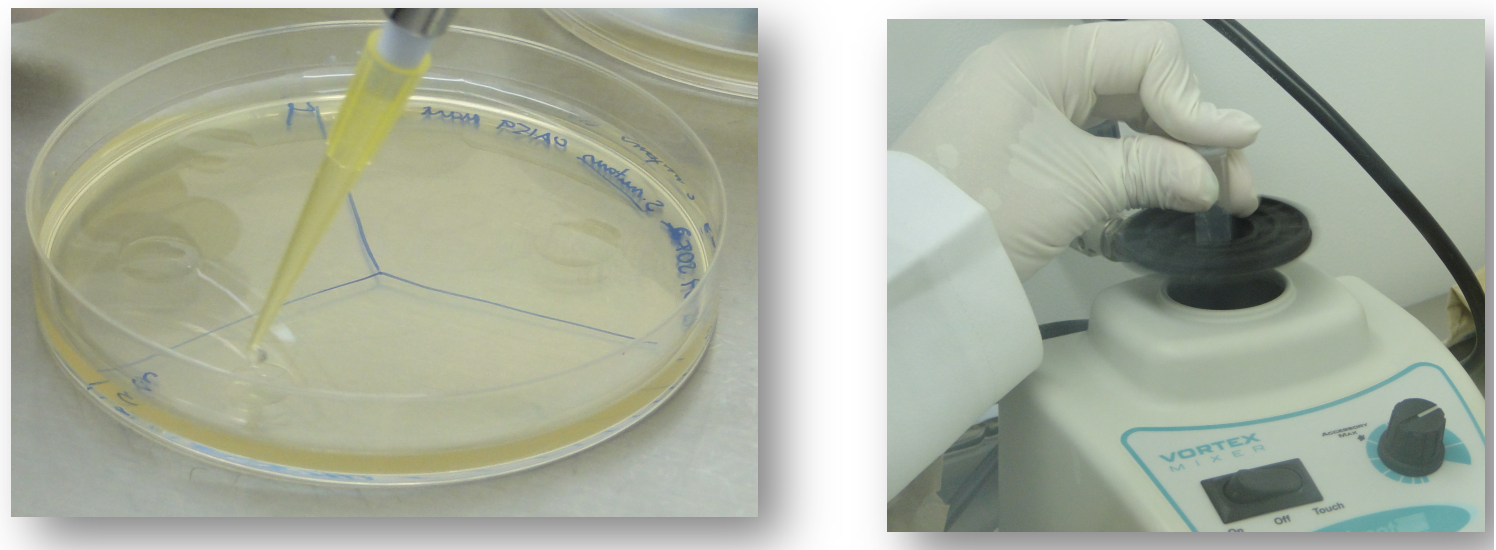

Análises da viabilidade bacteriana e dos polissacarídeos

Fluxograma 1: A. Confecção dos corpos de prova; B. Cultivo das cepas S. mutans UA 159; C. Plaqueamento (strick); D. Cultura iniciadora; E. Inoculação dos corpos de prova; F. Troca do meio; G. Tratamentos $(\mathrm{NaCl}$, Clorexidina e aPDT); H. Análises da viabilidade bacteriana e dos polissacarídeos. 

$\mathcal{R}_{\text {esultados }}$ 



\section{Resultados}

Os testes estatísticos revelaram que as contagens de bactérias nos biofilmes formados foram significativamente diferentes entre os tratamentos (Gráfico 1), mas a clorexidina apresentou maior inibição de biofilmes quando comparada à aPDT $(p<0,05)$. A concentração de polissacarídeo insolúvel $(P E C l)$ e polissacarídeo intracelular (PIC) (Tabela 1) foi maior no biofilme exposto ao $\mathrm{NaCl}$ do que a encontrada nos outros grupos $(p<0,05)$. No entanto, não foi observada diferença significativa entre os grupos clorexidina e aPDT $(p>0,05)$.

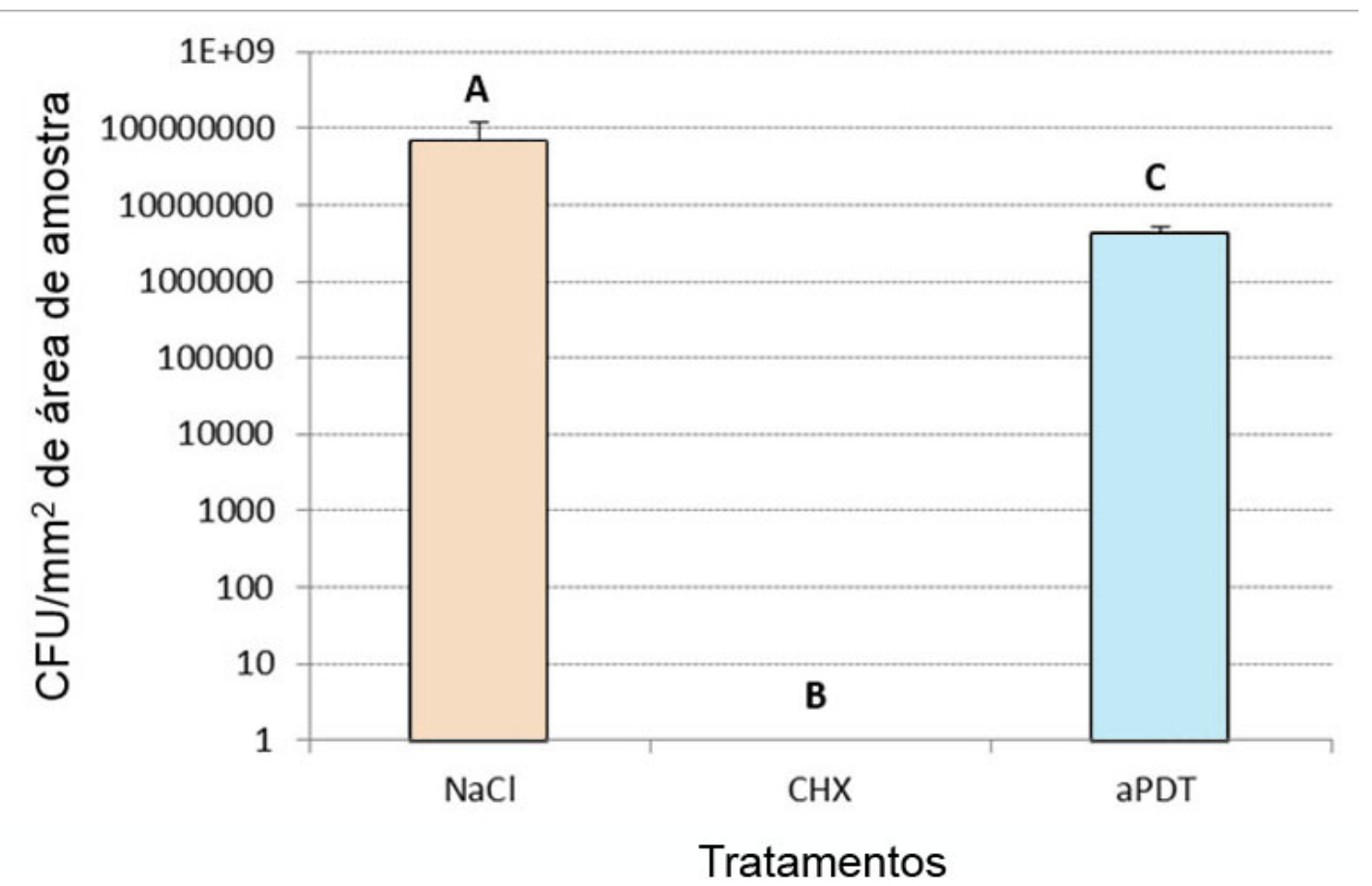

Gráfico 1: viabilidade do biofilme S. mutans de acordo com os tratamentos. Os dados foram submetidos à análise de variância (ANOVA) e comparados pelo teste de Tukey. Letras distintas indicam diferenças significativas entre os tratamentos $(p<0,05)$. NaCl $=0,9 \%$ de $\mathrm{NaCl} ; \mathrm{CHX}=0,12 \%$ de digluconato de clorexidina; aPDT = terapia fotodinâmica antimicrobiana empregando azul de metileno a $0,01 \%$ combinado ao laser de diodo $\left(\lambda=660 \mathrm{~nm} ; 320 \mathrm{~J} / \mathrm{cm}^{2} ; 100 \mathrm{~mW} ; 90 \mathrm{~s} ; 9 \mathrm{~J}\right)$. 
Tabela 1: Concentração dos polissacarídeos em biofilmes $S$. mutans após o tratamento (média \pm desvio padrão).

\begin{tabular}{ccc}
\hline Tratamentos & $\begin{array}{c}\text { PECl } \\
\left(\mu \mathrm{g} / \mathrm{mm}^{2} \text { área da }\right. \\
\text { amostra })\end{array}$ & $\begin{array}{c}\text { PIC } \\
\left(\mu \mathrm{g} / \mathrm{mm}^{2} \text { área da }\right. \\
\text { amostra })\end{array}$ \\
\hline $\mathrm{NaCl}$ & $2.36 \pm 0.39 \mathrm{~A}$ & $1.24 \pm 0.39 \mathrm{~A}$ \\
$\mathrm{CHX}$ & $0.88 \pm 0.40 \mathrm{~B}$ & $0.28 \pm 0.11 \mathrm{~B}$ \\
& & \\
aPDT & $0.65 \pm 0.15 \mathrm{~B}$ & $0.28 \pm 0.09 \mathrm{~B}$ \\
& $\mathrm{~F}: 30.37-\mathrm{p}:$ & $\mathrm{F}: 21.75-\mathrm{p}:$ \\
ANOVA & 0.0001 & 0.0004 \\
\hline
\end{tabular}

Os dados foram submetidos à análise de variância (ANOVA) e comparadas pelo teste de Tukey. $\mathrm{PECI}=$ polissacarídeo extracelular insolúvel; $\mathrm{PIC}=$ polissacarídeo intracelular. Médias com letras distintas indicam diferenças significativas entre os tratamentos $(p<0,05)$. NaCl $=0,9 \%$ de $\mathrm{NaCl}$; $\mathrm{CHX}=0,12 \%$ digluconato de clorexidina; aPDT = terapia fotodinâmica antimicrobiana empregando azul de metileno a 0,01\% combinado ao laser de diodo $\left(\lambda=660 \mathrm{~nm} ; 320 \mathrm{~J} / \mathrm{cm}^{2} ; 100 \mathrm{~mW} ; 90 \mathrm{~s} ; 9 \mathrm{~J}\right)$. 
$D_{\text {iscussão }}$ 



\section{DISCUSSÃO}

O digluconato de clorexidina é o antimicrobiano mais utilizado na Odontologia e pode atuar como coadjuvante no controle mecânico do biofilme em pacientes que não possuem ou perderam a capacidade de realizar uma higiene oral adequada (Varoni et al., 2012). O impacto do digluconato de clorexidina na viabilidade do biofilme foi confirmado em nosso estudo, por meio da redução da contagem bacteriana e de polissacarídeos em relação ao controle negativo ( $\mathrm{NaCl})$. A propriedade antimicrobiana do digluconato de clorexidina é atribuída à sua carga catiônica, que pode alterar as propriedades dos polissacarídeos, como a solubilidade e a hidrofobicidade (Hope; Wilson, 2004). No entanto, essa mesma propriedade é considerada a base do seu efeito colateral mais comum, a coloração extrínseca do dente (Watts; Addy, 2001). Assim, embora o digluconato de clorexidina seja considerado o antimicrobiano "padrão ouro" para o controle do biofilme (Varoni et al., 2012), a busca por terapias alternativas vem sendo investigada.

A aPDT consiste em um processo de duas etapas, no qual a fonte de luz, quando utilizada sem o fotossensibilizador, não expressa efeito antimicrobiano. 0 mesmo ocorre quando o fotossensibilizador é utilizado sozinho (Rolim et al., 2012). Assim, uma combinação entre esses dois agentes pode levar a uma sequência de eventos biológicos que resultam em morte dos micro-organismos (Sharman et al., 1999). No entanto, a influência dessa combinação nos fatores de virulência das bactérias cariogênicas é pouco discutida, o que torna aPDT uma estratégia alternativa para erradicar micro-organismos patogênicos (Sperandio et al., 2013). Por outro lado, no biofilme, as bactérias estão embebidas em uma matriz rica em polissacarídeo, que pode proteger as bactérias que estão organizadas sob a forma de biofilmes contra agentes antimicrobianos (Marsh et al., 2011). Assim, o agente 
antimicrobiano tem de ser capaz de se difundir na estrutura do biofilme e resultar em danos na sua organização. Nesse contexto, a hipótese nula de que a aPDT pode reduzir a viabilidade do biofilme $S$. mutans foi aceita. Nossos resultados sugerem que um tratamento realizado duas vezes por dia com aPDT, utilizando-se laser de diodo $\left(320 \mathrm{~J} / \mathrm{cm}^{2}\right)$ combinado ao azul de metileno, foi capaz de penetrar no biofilme, uma vez que ocorreu uma redução significativa na viabilidade bacteriana quando comparada com o controle negativo. Por outro lado, essa redução foi menor quando comparada com a aplicação da clorexidina. Possivelmente, pequenas alterações nos parâmetros do laser de diodo, como tempo de irradiação ou densidade de energia, poderiam melhorar os resultados, como sugerido por Alvarenga et al. (2015) e observado por Farias et al. (2016). Dessa forma, nossos resultados estão de acordo com estudos anteriores, nos quais a aPDT, utilizando-se laser diodo combinado ao azul de metileno, mostrou capacidade de reduzir bactérias em biofilmes de $S$. mutans (Guglielmi et al., 2011; Schneider et al., 2012; Pereira et al., 2011; Ricatto et al., 2014; Diniz et al., 2015).

Neste estudo, a hipótese nula de que a aPDT foi capaz de reduzir PECI foi aceita. Além de reduzir a viabilidade bacteriana em biofilmes de $S$. mutans, a aPDT promoveu uma diminuição na quantificação de polissacarídeo extracelular. O polissacarídeo insolúvel é considerado um fator de virulência crítico no biofilme dental formado na presença de sacarose, pois altera a estrutura do biofilme e aumenta suas propriedades cariogênicas (Klein et al., 2015). Considerando-se que até $40 \%$ do peso seco do biofilme são compostos por polissacarídeos (Paes-Leme et al., 2006), uma diminuição da quantidade desses polímeros pode prejudicar a estabilidade, modificar fisicamente a estrutura da matriz de polissacarídeo ou pode ter efeitos sobre a expressão enzimática da glicosiltransferase. Esse processo 
merece uma análise mais aprofundada, a fim de se avaliar o principal mecanismo de ação da aPDT em polissacarídeos insolúveis, uma vez que mudanças na matriz dos polissacarídeos do biofilme podem facilitar a limpeza mecânica dos biofilmes.

A hipóteses nula de que a aPDT foi capaz de reduzir o PIC foi aceita, uma vez que as diferença entre esse tratamento e o controle positivo, digluconato de clorexidina não foi estatisticamente significativa. $\mathrm{O}$ PIC é um polímero de armazenamento do tipo glicogênio, que proporciona ao $S$. mutans uma fonte endógena de hidratos de carbono que podem ser metabolizados quando substratos fermentáveis exógenos estiverem escassos (Busuioc et al., 2009). O efeito do PIC na cariogenicidade de S. mutans é bem estabelecido (Harris et al., 1992), uma vez que a produção de ácido pelas bactérias dissolve a hidroxiapatita (processo de desmineralização). Consequentemente, a diminuição do polissacarídeo pela aPDT pode contribuir para a perda das propriedades cariogênicas dos biofilmes de $S$. mutans.

Este estudo baseou-se no estudo de Guglielmi et al. (2011), no qual foi utilizado laser diodo $\left(\lambda=660 \mathrm{~nm} ; 320 \mathrm{~J} / \mathrm{cm}^{2} ; 100 \mathrm{~mW} ; 90 \mathrm{~s} ; 9 \mathrm{~J}\right)$, combinado ao azul de metileno, que obteve uma redução de $78,07 \%$ dos estreptococos do grupo mutans. Outros estudos utilizaram laser de diodo com resultados satisfatórios, porém a comparação entre eles é difícil, pois cada estudo utiliza parâmetros diferentes (Wilson et al., 1996; Pereira et al., 2011; Longo et al., 2012; Ricatto et al., 2014). Na Odontologia, os lasers mais usados são: hélio-neônio (633 nm) (O'Neil et al., 2002; Zanin et al., 2005) e o laser de diodo (630-690, 830, ou 906 nm) (Wilson; Burns,1996; Guglielmi et al., 2011; Schneider et al., 2012; Pereira et al., 2011; Ricatto et al., 2014). A escolha da fonte de luz, depende do corante utilizado, e do seu comprimento de onda que deve coincidir com o espectro de ativação do corante 
(Prates et al., 2007; Gursoy et al., 2013). Este trabalho utilizou o laser diodo que por ser de fácil de utilização, portátil e de baixo custo é o laser mais utilizado para aPDT, além disso, possuem um espectro estreito que permite uma interação mais específica com o fotossensibilizador (Soukos; Godson, 2000).

O fotossensibilizador escolhido foi $\mathrm{O}$ azul de metileno, um corante fenotiazínico que tem sido utilizado para reduzir o número de micro-organismos, devido às suas propriedades: baixa toxicidade às células humanas, alta taxa absorção no seu comprimento de onda e geração de espécies de oxigênio reativo que são citotóxicas para as bactérias (Wainwright et al., 1998; Usacheva et al., 2003). Além disso, devido à sua carga positiva, o azul de metileno é capaz de penetrar de forma mais eficiente nas paredes celulares dos micro-organismos carregados negativamente, melhorando a ação da aPDT. Sabe-se que o azul de metileno é um composto heteroaromático tricíclicos, que são responsáveis pela fotossensibilização das bactérias (Usacheva et al., 2003) e não induzem efeitos citotóxicos sobre fibroblastos humanos e células do ligamento periodontal (Qiao et al., 2014). Devido a essas características, o azul de metileno é um dos corantes mais utilizados em estudos experimentais e em aplicações clínicas em odontologia (Guglielmi et al., 2011; ; Pereira et al., 2011; Schneider et al., 2012; Ricatto et al., 2014; Cieplik, et al., 2014; Steiner-Oliveira et al., 2015), o que justiça sua escolha para o presente estudo.

O tempo de pré-irradiação pode ser um fator importante para a difusão do fotossensibilizador (Guglielmi et al., 2011). Em nosso estudo, os corpos de prova que receberam aPDT como tratamento foram imersos durante 5 minutos, no escuro, em uma solução de azul de metileno a 0,01\% antes da irradiação com laser de diodo. Outros trabalhos (Guglielmi et al., 2011; Pereira et al., 2011; Araújo et al., 
2015) usam esse tempo, sendo demonstrado que um tempo de pré-irradiação menor (60 S), o efeito na viabilidade é pequeno (Müller et al., 2007).

Todos os modelos experimentais têm pontos favoráveis e desfavoráveis. O que deve ser considerado é a validade do modelo em relação à doença (Bowen, 2015). O presente estudo utilizou um modelo de biofilme validado (CcahuanaVásquez; Cury, 2010), que simula condições similares às que ocorrem na cavidade bucal, na qual uma dieta rica em carboidratos é simulada pela exposição à sacarose oito vezes ao dia. Dessa forma, considerando a capacidade das bactérias em hidrolisar açúcares para produzir polissacarídeos extras e intracelulares, esse modelo foi capaz de alcançar o objetivo do estudo, uma vez que as bactérias sob forma de modelo de biofilme diferem das bactérias em fase planctônicas em relação à presença de PEC e PIC, composição da parede celular, taxa de crescimento e a atividade metabólica (Costerton et al., 1999). No entanto, a compreensão dos mecanismos moleculares de aPDT e os seus efeitos sobre biofilmes multiespécies devem ser avaliados no futuro. 

Conclusão 



\section{Conclusão}

De acordo com as condições experimentais do presente estudo, sugere-se que o tratamento com aPDT, com a utilização de azul de metileno a $0,01 \%$ combinado ao laser de diodo $\left(\lambda=660 \mathrm{~nm} ; 320 \mathrm{~J} / \mathrm{cm}^{2} ; 100 \mathrm{~mW} ; 90 \mathrm{~s} ; 9 \mathrm{~J}\right)$ :

1. diminuiu a viabilidade do biofilme de $S$. mutans.

2. reduziu o polissacarídeo insolúvel e o polissacarídeo intracelular, afetando a organização estrutural do biofilme. 

$\mathcal{R}_{\text {eferências }}$ 



\section{REFERÊNCIAS}

Aires CP, Del Bel Cury AA, Tenuta LM, Klein MI, Koo H, Duarte S, Cury JA. Effect of starch and sucrose on dental biofilm formation and on root dentine demineralization. Caries Res. 2008;42:380-6.

Alvarenga LH, Prates RA, Yoshimura TM, Kato IT, Suzuki LC, Ribeiro MS, Ferreira LR, Pereira SA, Martinez EF, Saba-Chujfi E. Aggregatibacter actinomycetemcomitans biofilm can be inactivated by methylene blue-mediated photodynamic therapy. Photodiagnosis Photodyn Ther. 2015;12:131-5.

Araújo PV, Correia-Silva J de F, Gomez RS, Massara M de L, Cortes ME, Poletto LT. Antimicrobial effect of photodynamic therapy in carious lesions in vivo, using culture and real-time PCR methods. Photodiagnosis Photodyn Ther. 2015;12:401-7.

Araújo NC, Fontana CR, Bagnato VS, Gerbi ME. Photodynamic antimicrobial therapy of curcumin in biofilms and carious dentine. Lasers Med Sci. 2014;29:629-35.

Athar M, Mukhtar H, Elmets CA, Zaim MT, Lloyd JR, Bickers DR. In situ evidence for the involvement of superoxide anions in cutaneous porphyrin photosensitization. Biochem Biophys Res Commun. 1988;151:1054-9.

Bevilacqua IM, Nicolau RA, Khouri S, Brugnera A Jr, Teodoro GR, Zângaro RA, Pacheco MT. The impact of photodynamic therapy on the viability of Streptococcus mutans in a planktonic culture. Photomed Laser Surg. 2007;25:513-8.

Bowen WH. Do we need to be concerned about dental caries in the coming millennium? Crit Rev Oral Biol Med. 2002;13:126-31.

Bowen WH. Dental caries - not just holes in teeth! A perspective. Mol Oral Microbiol. 2015.

Bradshaw DJ, Marsh PD. Analysis of $\mathrm{pH}$-driven disruption of oral microbial communities in vitro. Caries Res. 1998;32:456-62.

Burns T, Wilson M, Pearson GJ. Sensitisation of cariogenic bacteria to killing by light from a helium/neon laser. J Med Microbiol. 1993;8:182-7.

Burns T, Wilson M, Pearson G J. Killing of cariogenic bacteria by light from a gallium aluminium arsenide diode laser. J. Dent. 1994;22:273-2.

Burns T, Wilson M, Pearson GJ. Effect of dentine and collagen on the lethal photosensitization of Streptococcus mutans. Caries Res. 1995;29:192-7.

Busuioc M, Mackiewicz K, Buttaro BA, Piggot PJ. Role of intracelular polysaccharide in persistence of Streptococcus mutans. J Bacteriol. 2009;191:7315-22.

Ccahuana-Vásquez RA, Cury JA. S. mutans biofilm model to evaluate antimicrobial substances and enamel demineralization. Braz Oral Res. 2010;24:135-41.

Cappuyns I, Cionca N, Wick P, Giannopoulou C, Mombelli A. Treatment of residual pockets with photodynamic therapy, diode laser, or deep scaling. A randomized, split-mouth controlled clinical trial. Lasers Med Sci. 2012;27:979-86. 
Cieplik F, Tabenski L, Buchalla W, Maisch T. Antimicrobial photodynamic therapy for inactivation of biofilms formed by oral key pathogens. Front Microbiol. 2014;5:1-17.

Costa AC, Chibebe Junior J, Pereira CA, Machado AK, Beltrame Junior M, Junqueira JC, Jorge AO. Susceptibility of planktonic cultures of Streptococcus mutans to photodynamic therapy with a light-emitting diode. Braz Oral Res. 2010;24:413-8.

Costerton JW, Stewart PS, Greenberg EP. Bacterial biofilms: a common cause of persistent infections. Science. 1999;284(5418):1318-22.

Dai T, Huang YY, Hamblin MR. Photodynamic therapy for localized infections--state of the art. Photodiagnosis Photodyn Ther. 2009;6:170-88.

Diniz IM, Horta ID, Azevedo CS, Elmadjian TR, Matos AB, Simionato MR, Marques MM. Antimicrobial photodynamic therapy: a promise candidate for caries lesions treatment. Photodiagnosis Photodyn Ther. 2015;12:511-8.

Dubois M, Gillis KA, Hamilton JK, Rebers PA, Smith F: Colorimetric method for determination of sugars and related substances. Analyt Chem. 1956;28:350-6.

Dougherty TJ, Gomer CJ, Henderson BW, Jori G, Kessel D, Korbelik M, Moan J, Peng Q. Photodynamic therapy. J Natl Cancer Inst. 1998;90:889-905.

Farias SSS, Efeito da terapia fotodinâmica antimicrobiana no controle do biofilme cariogênico. 2015. 82 f. Dissertação (Mestrado em ciências, área de concentração em Odontopediatria) - Faculdade de Odontologia de Ribeirão Preto, Universidade de São Paulo, São Paulo. 2001.

Flotra L. Different modes of chlorhexidine application and related local side effects. J Periodontal Res Suppl. 1973;12:41-4.

Garcez AS, Núñez SC, Azambuja N Jr, Fregnani ER, Rodriguez HM, Hamblin MR, Suzuki H, Ribeiro MS. Effects of photodynamic therapy on Gram-positive and Gramnegative bacterial biofilms by bioluminescence imaging and scanning eléctron microscopic analysis. Photomed Laser Surg. 2013;31:519-25.

Goulart R de C, Bolean M, Paulino T de P, Thedei G Jr, Souza SL, Tedesco AC, Ciancaglini P. Photodynamic therapy in planktonic and biofilm cultures of Aggregatibacter actinomycetemcomitans. Photomed Laser Surg. 2010;28:53-60.

Guglielmi C de A, Simionato MR, Ramalho KM, Imparato JC, Pinheiro SL, Luz MA. Clinical use of photodynamic antimicrobial chemotherapy for the treatment of deep carious lesions. J Biomed Opt. 2011;16(8):088003-7.

Gursoy H, Ozcakir-Tomruk C, Tanalp J, Yilmaz S. Photodynamic therapy in dentistry: a literature review. Clin Oral Investig. 2013;17:1113-25.

Hakimiha N, Khoei F, Bahador A, Fekrazad R. The susceptibility of Streptococcus mutans to antibacterial photodynamic therapy: a comparison of two different photosensitizers and light sources. J Appl Oral Sci. 2014;22:80-4.

Hamada S, Slade HD. Biology, immunology, and cariogenicity of Streptococcus mutans. Microbiol Rev. 1980;44:331-84. 
Harris GS, Michalek SM, Curtiss R 3rd. Cloning of a locus involved in Streptococcus mutans intracellular polysaccharide accumulation and virulence testing of an intracellular polysaccharide-deficient mutant. Infect Immun. 1992;60:3175-85.

Hidalgo E, Dominguez C. Mechanisms underlying chlorhexidine-induced cytotoxicity. Toxicol In Vitro. 2001;15:271-6.

Hope CK, Wilson M. Analysis of the effects of chlorhexidine on oral biofilm vitality and structure based on viability profiling and an indicator of membrane integrity. Antimicrob Agents Chemother. 2004;48:1461-8.

Jenkins S, Addy M, Wade W. The mechanism of action of chlorhexidine. A study of plaque growth on enamel inserts in vivo. J Clin Periodontol. 1988;15:415-24.

Karpiński TM, Szkaradkiewicz AK. Chlorhexidine--pharmaco-biological activity and application. Eur Rev Med Pharmacol Sci. 2015;19:1321-6.

Kishen A, Upadya M, Tegos GP, Hamblin MR. Efflux pump inhibitor potentiates antimicrobial photodynamic inactivation of Enterococcus faecalis biofilm. Photochem Photobiol. 2010;86:1343-9.

Klein MI, Hwang G, Santos PH, Campanella OH, Koo H. Streptococcus mutansderived extracellular matrix in cariogenic oral biofilms. Front Cell Infect Microbiol. 2015;5:1-10.

Kömerik N, Nakanishi H, MacRobert AJ, Henderson B, Speight P, Wilson M. In vivo killing of Porphyromonas gingivalis by toluidine blue-mediated photosensitization in an animal model. Antimicrob Agents Chemother. 2003;47:932-40.

Konan YN, Gurny R, Allémann E. State of the art in the delivery of photosensitizers for photodynamic therapy. J Photochem Photobiol B. 2002;66:89-106.

Kumar JV, Green EL. Oral health disparities in New York State. N Y State Dent J. 2005;71:43-7.

Lang NP, Hotz P, Graf H, Geering AH, Saxer UP, Sturzenberger OP, Meckel AH. Effects of supervised chlorhexidine mouthrinses in children. A longitudinal clinical trial. J Periodontal Res. 1982;17:101-11.

Loe H, Silness J. Periodontal Disease In Pregnancy. I. Prevalence And Severity. Acta Odontol Scand. 1963;21:533-51.

Lima JP, Sampaio de Melo MA, Borges FM, Teixeira AH, Steiner-Oliveira C, Nobre Dos Santos M, Rodrigues LK, Zanin IC. Evaluation of the antimicrobial effect of photodynamic antimicrobial therapy in an in situ model of dentine caries. Eur J Oral Sci. 2009;117:568-74.

Mah TF, O'Toole GA. Mechanisms of biofilm resistance to antimicrobial agents. Trends Microbiol. 2001; 9:34-9.

Mang TS, Tayal DP, Baier R. Photodynamic therapy as an alternative treatment for disinfection of bacteria in oral biofilms. Lasers Surg Med. 2012;44:588-96. 
Marsh PD. Sugar, fluoride, $\mathrm{pH}$ and microbial homeostasis in dental plaque. Proc Finn Dent Soc. 1991;87:515-25.

Marsh PD. Dental plaque as a microbial biofilm. Caries Res. 2004;38:204-11.

Marsh PD, Moter A, Devine DA. Dental plaque biofilms: communities, conflict and control. Periodontol 2000. 2011;55:16-35.

Monzavi A, Chinipardaz Z, Mousavi M, Fekrazad R, Moslemi N, Azaripour A, Bagherpasand $\mathrm{O}$, Chiniforush N. Antimicrobial photodynamic therapy using diode laser activated indocyanine green as an adjunct in the treatment of chronic periodontitis: A randomized clinical trial. Photodiagnosis Photodyn Ther. 2016; S1572-1000(16)30019-9.

Müller P, Guggenheim B, Schmidlin PR. Efficacy of gasiform ozone and photodynamic therapy on a multispecies oral biofilm in vitro. Eur $\mathrm{J}$ Oral Sci. 2007;115:77-80.

Nobre dos Santos M, Melo dos Santos L, Francisco SB, Cury JA. Relationship among dental plaque composition, daily sugar exposure and caries in the primary dentition. Caries Res. 2002;36:347-52.

Novaes AB Jr, Schwartz-Filho HO, de Oliveira RR, Feres M, Sato S, Figueiredo LC. Antimicrobial photodynamic therapy in the non-surgical treatment of aggressive periodontitis: microbiological profile. Lasers Med Sci. 2012;27:389-95.

Paes-Leme AF, Koo H, Bellato CM, Bedi G, Cury JA. The role of sucrose in cariogenic dental biofilm formation--new insight. J Dent Res. 2006;85:878-87.

Parisotto TM, Stipp R, Rodrigues LK, Mattos-Graner RO, Costa LS, Nobre-DosSantos M. Can insoluble polysaccharide concentration in dental plaque, sugar exposure and cariogenic microorganisms predict early childhood caries? A follow-up study. Arch Oral Biol. 2015;60:1091-7.

Pereira CA, Romeiro RL, Costa AC, Machado AK, Junqueira JC, Jorge AO. Susceptibility of Candida albicans, Staphylococcus aureus, and Streptococcus mutans biofilms to photodynamic inactivation: an in vitro study. Lasers Med Sci. 2011;26:341-8.

Prates RA, Yamada AM Jr, Suzuki LC, Eiko Hashimoto MC, Cai S, Gouw-Soares S, Gomes L, Ribeiro MS. Bactericidal effect of malachite green and red laser on Actinobacillus actinomycetemcomitans.J Photochem Photobiol B. 2007;86:70-6.

Ochsner M. Photophysical and photobiological processes in the photodynamic therapy of tumours. J Photochem Photobiol B. 1997;39:1-18.

Oliveira RR, Schwartz-Filho HO, Novaes AB, Garlet GP, de Souza RF, Taba M, Scombatti de Souza SL, Ribeiro FJ. Antimicrobial photodynamic therapy in the nonsurgical treatment of aggressive periodontitis: cytokine profile in gingival crevicular fluid, preliminary results. J Periodontol. 2009;80:98-105.

O'Neill JF, Hope CK, Wilson M. Oral bacteria in multi-species biofilms can be killed by red light in the presence of toluidine blue. Lasers Surg Med. 2002; 31: 86-90. 
Quishida CC, Mima EG, Dovigo LN, Jorge JH, Bagnato VS, Pavarina AC. Photodynamic inactivation of a multispecies biofilm using Photodithazine( $\left({ }^{\circledR}\right)$ and LED light after one and three successive applications. Lasers Med Sci. 2015;30:2303-12.a

Quishida CC, Carmello JC, Mima EG, Bagnato VS, Machado AL, Pavarina AC. Susceptibility of multispecies biofilm to photodynamic therapy using Photodithazine ${ }^{\circledR}$. Lasers Med Sci. 2015;30:685-94.b

Ricatto LG, Conrado LA, Turssi CP, França FM, Basting RT, Amaral FL. Comparative evaluation of photodynamic therapy using LASER or light emitting diode on cariogenic bacteria: An in vitro study. Eur J Dent. 2014;8:509-14.

Redmond RW, Gamlin JN. A compilation of singlet oxygen yields from biologically relevant molecules. Photochem Photobiol. 1999;70:391-475.

Rolim JP, de-Melo MA, Guedes SF, Albuquerque-Filho FB, de Souza JR, Nogueira NA, Zanin IC, Rodrigues LK. The antimicrobial activity of photodynamic therapy against Streptococcus mutans using different photosensitizers. J Photochem Photobiol B. 2012;106:40-6.

Santin GC, Oliveira DS, Galo R, Borsatto MC, Corona SA. Antimicrobial photodynamic therapy and dental plaque: a systematic review of the literature. Scientific World Journal. 2014;2014:1-9.

Schneider M, Kirfel G, Berthold M, Frentzen M, Krause F, Braun A. The impact of antimicrobial photodynamic therapy in an artificial biofilm model. Lasers Med Sci. 2012;27:615-20.

Sharman WM, Allen CM, van Lier JE. Photodynamic therapeutics: basic principles and clinical applications. Drug Discov Today. 1999;4:507-17.

Sigusch BW, Engelbrecht M, Völpel A, Holletschke A, Pfister W, Schütze J. Full mouth antimicrobial photodynamic therapy in Fusobacterium nucleatum-infected periodontitis patients. J Periodontol. 2010;81:975-81.

Soukos NS, Goodson JM. Photodynamic therapy in the control of oral biofilms. Periodontol 2000. 2011;55:143-66.

Sperandio FF, Huang YY, Hamblin MR. Antimicrobial photodynamic therapy to kill Gram-negative bacteria. Recent Pat Antiinfect Drug Discov. 2013;8:108-20.

Staat RH, Gawronski TH, Cressey DE, Harris RS, Folke LE. Effects of dietary sucrose levels on the quantity and microbial composition of human dental plaque. $J$ Dent Res. 1975;54:872-80.

Stabholz A, Zeltser R, Sela M, Peretz B, Moshonov J, Ziskind D, Stabholz A. The use of lasers in dentistry: principles of operation and clinical applications. Compend Contin Educ Dent. 2003; 24:935-48.

Steiner-Oliveira C, Longo PL, Aranha AC, Ramalho KM, Mayer MP, de Paula Eduardo C. Randomized in vivo evaluation of photodynamic antimicrobial chemotherapy on deciduous carious dentin. J Biomed Opt. 2015;20:108003-7. 
De Stoppelaar JD, Van Houte J, Backer DIRKS O. The effect of carbohydrate restriction on the presence of Streptococcus mutans, Streptococcus sanguis and iodophilic polysaccharide-producing bacteria in human dental plaque. Caries Res. 1970;4:114-23.

Street CN, Pedigo LA, Loebel NG. Energy dose parameters affect antimicrobial photodynamic therapy-mediated eradication of periopathogenic biofilm and planktonic cultures. Photomed Laser Surg. 2010;28:61-6.

Teixeira AH, Pereira ES, Rodrigues LK, Saxena D, Duarte S, Zanin IC. Effect of photodynamic antimicrobial chemotherapy on in vitro and in situ biofilms. Caries Res. 2012;46:549-54.

Tenuta LM, Ricomini Filho AP, Del Bel Cury AA, Cury JA: Effect of sucrose on the selection of mutans streptococci and lactobacilli in dental biofilm formed in situ. Caries Res. 2006;40:546-9.

Thurnheer T, Gmür R, Shapiro S, Guggenheim B. Mass transport of macromolecules within an in vitro model of supragingival plaque. Appl Environ Microbiol. 2003;69:1702-9.

Twetman S. Antimicrobials in future caries control? A review with special reference to chlorhexidine treatment. Caries Res. 2004;38:223-9.

Usacheva MN, Teichert MC, Biel MA. The interaction of lipopolysaccharides with phenothiazine dyes. Lasers Surg Med. 2003;33:311-9.

Varoni E, Tarce M, Lodi G, Carrassi A. Chlorhexidine (CHX) in dentistry: state of the art. Minerva Stomatol. 2012;61:399-419.

Wainwright $M$. The development of phenothiazinium photosensitisers. Photodiagnosis Photodyn Ther. 2005;2:263-72.

Watts A, Addy M. Tooth discolouration and staining: a review of the literature. $\mathrm{Br}$ Dent J. 2001;190:309-16.

Wilson M, Burns T, Prarten J Killing of Streptococcus sanguis in biofilms using a light-activated antimicrobial agent. J Antimicrob Chemother. 1996;37:377-81.

Wilson M. Lethal photosensitisation of oral bacteria and its potential application in the photodynamic therapy of oral infections. Photochem Photobiol Sci. 2004;3:412- 8.

Wood S, Nattress B, Kirkham J. Shore R., Brookes S. Griffiths J, Robinson C. An in vitro study of the use of photodynamic therapy for the treatment of natural oral plaque biofilms formed in vivo. J Photochem Photobiol B.1999; 50: 1-7.

Wood S, Metcalf D, Devine D, Robinson C. Erythrosine is a potential photosensitizer for the photodynamic therapy of oral plaque biofilms. J Antimicrob Chemother. 2006; 57:680-4.

Zanin IC, Gonçalves RB, Junior AB, Hope CK, Pratten J. Susceptibility of Streptococcus mutans biofilms to photodynamic therapy: an in vitro study. J Antimicrob Chemother. 2005;56:324-30. 
Zanin IC, Lobo MM, Rodrigues LK, Pimenta LA, Höfling JF, Gonçalves RB. Photosensitization of in vitro biofilms by toluidine blue $\mathrm{O}$ combined with a lightemitting diode. Eur J Oral Sci. 2006;114:64-9. 